\title{
Crítica moral de Francis Bacon a la filosofía
}

\author{
Francis Bacon's moral critique to philosophy
}

Maximiliano Prada Dussán1

Resumen

Este escrito muestra la crítica moral de Bacon a la filosofía, presente en sus obras de juventud, la cual es desarrollada en tres niveles: primero, los cargos a la filosofía por su inutilidad, segundo, las acusaciones a la falta de verdad y de método y, finalmente, la denuncia de falta de caridad y humildad. En conclusión, este estudio intentará sustentar que 1. La reforma baconiana no se restringe a un nuevo método ni a una nueva teoría de la materia; más allá de esto, encuentra un sustento en una nueva posición moral del hombre frente a la naturaleza, y 2. Que su proyecto epistemológico encuentra sentido en el trasfondo moral.

\section{Palabras clave}

Francis Bacon, filosofía del siglo XVII, filosofía inglesa, filosofía moral.

\section{Abstract}

This paper is about Bacon's moral critique to philosophy. This critique is present in his youth work and it is developed in three levels: first, charges against philosophy because of its uselessness; second, accusations against philosophy's lack of truth and method; and, finally, charges against philosophy's lack of charity and humility. Briefly, this study will state and support two hypotheses. 1. Bacon's reform is not restricted to a new method neither a new theory of matter; beyond this; it is a new moral position about man in relation to nature. 2. His epistemological project makes sense in the moral background.

Keywords

Francis Bacon, Seventeenth-Century philosophy, english philosophy, moral philosophy.

Artículo recibido 31 de julio de 2009 y aprobado el 31 de julio de 2009.

1 Magister en Filosofía. Profesor de la Universidad Pedagógica Nacional. Correo electrónico: aprada@pedagogica.edu.co 
No ha habido una única línea de interpretación a la hora de responder a la pregunta por la importancia de Francis Bacon en el nacimiento de la filosofía moderna y en la revolución científica del siglo XVII. No siempre las distintas aproximaciones que la ciencia y la filosofía posteriores a Bacon han hecho sobre el filósofo inglés han llegado a acuerdos a la hora de precisar sus aportes a la construcción de dicho proyecto. Aspectos como la importancia del método inductivo para el desarrollo e investigación en la ciencia, la relación entre la utilidad y verdad, la instauración de una tecnocracia o, incluso, las fuentes principales de su obra son algunos de los asuntos que ocupan a investigadores y sobre los cuales se suelen encontrar posiciones distintas.

No han faltado, tampoco, críticas al proyecto baconiano, en especial aquellas que lo acusan de desarrollar una ciencia de ingenieros, esto es, un saber que sólo propende al desarrollo de artefactos y obras, las que lo acusan de haber subordinado la verdad a la utilidad, o las que desechan su método inductivo, entre otras acusaciones.

De manera introductoria, nos referiremos a dos de las posturas más comunes: la primera de ellas se refiere al interés que se ha puesto en aspectos epistemológicos, especialmente, con el método inductivo de la ciencia; interés despertado en el siglo XIX por autores como John Herschel (1791-1871), el historiador de la ciencia William Whewell (17941866) y el filósofo John Stuart Mill (1806-1873), y que ha tenido respuesta en el rechazo del método baconiano en la ciencia por parte de autores como Koyré (1981, p. 2), Lakatos (1968, p. 318) y Popper (Pérez-Ramos, 1988, pp. 18-29). La segunda postura es la acusación que se ha hecho a Bacon de promover un tecnicismo que se expande desde la producción de artefactos hacia los demás dominios humanos sin restricción alguna, incluidos los dominios ético y político. De acuerdo con la interpretación que de él hicieran Horkheimer y Adorno (1994, p. 60), Bacon aparece como promotor del utilitarismo o como el germen del dominio de la razón instrumental2.

2 Vale anotar que estas dos interpretaciones sobre Bacon guían los estudios introductorios de las dos traducciones más difundidas que tenemos al español del Novum Organum. Intentando valorar su obra, Risieri Frondizi afirma que "lo que más cuenta de su contribución debe buscarse en su metodología" (2003, p. 11). Por su parte, Francisco Larroyo señala que Bacon extiende el saber técnico a los
Tales críticas han hecho que en ocasiones se olviden aspectos centrales del proyecto baconiano o que Bacon sea considerado como un autor de poca importancia para el pensamiento filosófico y científico. No obstante, como se intentará mostrar en este artículo, Bacon concibe el proyecto de renovación metodológica de la filosofía natural y su posterior efecto en el bienestar humano a partir de la transformación de las condiciones materiales, enlazado íntimamente a una reforma moral de la filosofía y de los filósofos; enlace que ante un marcado énfasis de la interpretación en aspectos epistemológicos ha sido relegado a un segundo plano. En este sentido, en términos generales, se pretende mostrar que interrogantes relacionados con las críticas mencionadas (tales como la idea de dominio del hombre sobre el hombre, la idea de beneficio material o, incluso, el matiz que toma el método inductivo) adquieren un carácter distinto, una vez se estudia la epistemología baconiana enlazada a la moral e incluso que aspectos centrales de su reforma encuentran justificación también en este terreno.

Si bien en su obra cumbre, Novum Organum, el autor inglés centró su interés en aspectos metodológicos, se puede encontrar que su proyecto de filosofía natural está soportado por consideraciones morales, desarrolladas fundamentalmente en sus obras de juventud3; en estas obras, Bacon intenta enlazar -y hasta de cierto modo justificar- aspectos de la construcción de la filosofía natural con consideraciones morales, religiosas y teológicas. Allí, Bacon encuentra que los errores propios de la investigación de filosofía natural están relacionados

campos político, económico y moral: “También en estas zonas hay que encauzar la acción de los hombres de manera técnica" (2000, pp. xxiv-xxv). Esto muestra que en nuestro contexto hispanohablante de interpretación y estudio del filósofo inglés, éstas son las interpretaciones que se han difundido. Como se verá más adelante, en otros contextos, la interpretación sobre Bacon ha cambiado, pero estos cambios no se han visto reflejados en estudios recientes en lengua española. Graham Rees (2002, pp. 379-374) ha elaborado una síntesis sobre las interpretaciones recientes de Bacon.

3 Obras que abarcan el periodo 1603-1609, entre las cuales se encuentran Temporis Partus Masculus (1603), Valerius Terminus of the interpretation of nature, with annotations by Hermes Stella (1603), Cogitationes de Natura Rerum (1604), The Proficience and Advancement of learning, Divine and Human (1605), Filium Labyrinthi sive Formula Inquisitions (1606), Cogitata et visa de Interpretatione Nature (1607), Redargutio Philosophiarum (1608) y De Sapientia Veterum (1609). En concreto, nos centraremos en las obras Valerius Terminus (1603), edición de 1850; The Advancement of Learning (1605), edición de 1988; y Redargutio Philosophiarum (1608), edición de 1985. 
con la falta de virtudes morales de los filósofos. Nuestro trabajo, en el presente escrito, consiste, precisamente, en mostrar la relación que hay entre los fines y métodos de la filosofía natural ${ }^{4}$ con las virtudes morales -cristianas, en este caso- que Bacon examina en los filósofos; mostraremos que para Bacon el proyecto epistemológico encuentra sentido en estas virtudes e, incluso, que dichas virtudes marcan caminos por los cuales debe conducirse a la investigación. Así, mostraremos que los puntos que Bacon considera centrales en la crítica a la filosofía, los fines del conocimiento y el método de demostración ${ }^{5}$, son aunados a la caridad y la humildad,

4 Si bien -esto será aclarado más adelante- podemos decir por el momento que por principios, Bacon entiende el fin último del conocimiento y por formas de demostración, el método por el cual la filosofía construye sus tesis. Por los primeros, se refiere a la idea de que el conocimiento debe servir para la construcción de obras y no de discursos admirables 0 argumentos satisfactorios. En cuanto al método, a la necesidad de una nueva inducción y al abandono de la silogística y la inducción antigua como caminos de la filosofía. (Bacon, 1850b, p. 88). Ver también (Bacon, 2003a, pp. 55-56): “Pues propónese como fin a esta ciencia, no el encontrar argumentos sino artes, ni lo lógico para los principios, sino los principios mismos, ni las razones probables sino las disposiciones e indicaciones de las obras. Y así, de una intención diversa síguese un efecto diverso. Pues allí se vence y constriñe al adversario por la disputa, aquí a la naturaleza por la obra. Con un fin semejante están de acuerdo la naturaleza y el orden de las demostraciones mismas. Pues en la lógica vulgar casi todo el esfuerzo se consume en el silogismo. Más los dialécticos no parece que hayan pensado seriamente apenas acerca de la inducción; trasmitiéndola con una leve mención y acordando apresuradamente las fórmulas de la disputa. Yo, en cambio, rechazo la demostración por el silogismo, porque procede un tanto confusamente y saca la naturaleza de las manos. Pues aun cuando no pueda ser dudoso a nadie que las cosas que convienen en el término medio convienen también entre sí (lo que es en cierto modo una verdad matemática), sin embargo hay latente este fraude, el que el silogismo consta de proposiciones, (55) y las proposiciones son palabras y las palabra son signos y señas de las nociones. Así pues, si las nociones mismas de la mente (que son como el alma de las palabras y base de toda su estructura y fábrica), están extraídas mal $y$ a la ligera de las cosas, y son vagas y no bien definidas, y limitadas. Finalmente, viciosas de múltiples maneras, todo cae por el suelo. Así, pues, rechazo el silogismo; y esto no sólo en cuanto a los principios (en orden a los cuales ellos no lo emplean), sino también en cuanto a las proposiciones medias, las que el silogismo saca y engendra de cualquier manera que sea estéril, empero, para las obras y apartada de la práctica e incompetente en absoluto en cuanto a la parte activa de las ciencias".

5 “Si quisiéramos abordarlos más de cerca [los sistemas filosóficos] para combatirlos uno a uno, sería en vano, por haber sido suprimida la norma de la disputación al no estar de acuerdo en los principios, y mucho más puesto que rechazamos las formas mismas de las pruebas y las demostraciones, así como su validez". (Bacon, 1985, p. 62). La fórmula se repite en el Novum Organum así: "pero intentar y acometer su refutación estaría en pleno desacuerdo con lo que llevamos dicho hasta aquí, pues como no estamos de acuerdo ni en los principios ni en las demostraciones, estaría de más toda argumentación" (Bacon, 2003b, pp. I. ixi). respectivamente ${ }^{6}$. Ahora bien, esta preocupación moral por la filosofía, si bien no es desarrollada por Bacon sistemáticamente, podemos decir que permanece en el desarrollo de sus obras aunque no abordadas directamente. Si bien no es el asunto central de este artículo brindar mayor sustento a esta tesis, incluimos algunas referencias al Novum Organum que evidencian esto 7 .

Antes de proponer un nuevo proyecto filosófico, Bacon ve que es necesario justificar la necesidad del cambio de la filosofía. Esta doble estructura de sus textos tiene también un cometido doble: por la parte destructiva, muestra los errores de la filosofía; por la parte constructiva, muestra su propuesta para salir de ellos 8 . De este modo, sostenemos que para comprender el sentido de la reforma baconiana de la filosofía y los rumbos que esta toma es necesario examinar primero cómo entiende el estado de la filosofía de su momento y las críticas que levanta sobre ella.

Esta búsqueda nos lleva a considerar niveles de la crítica, los cuales estructuran los subtítulos de este texto: el primero de ellos comienza cuando Bacon

6 Existen ya numerosos trabajos que resaltan el sentido moral de la filosofía baconiana y su enlace con la investigación de la filosofía natural (Gaukroger, 2004, p. 112; Sargent, 1999, pp. 146-171; 2002, p. 129; 2005, pp. 71-80 y 137; Box, 1999, p. 265; Channing Brings, 1999, pp. 260-282; Tovey, 1952, pp. 568 y ss.).

7 Estamos de acuerdo con Milner (1997, p. 264) en que a obra cumbre de Bacon se encuentran aún vestigios de este trasfondo moralreligioso desarrollado en las obras de juventud.

8 Dos de los intentos más claros de sistematizar la estructura doble (crítica y construcción) se encuentran en El avance del saber y en el Novum Organum. El primer libro del Advancement, Bacon lo desarrolla en dos partes: "una primera relativa a la excelencia del saber y del conocimiento, y la excelencia del mérito y verdadera gloria que hay en su aumento y propagación, y una segunda relativa a cuáles sean las acciones y obras particulares que han sido puestas en práctica y emprendidas en orden al progreso del saber, y también a qué defectos e imperfecciones encuentro yo en tales actos particulares" (Bacon, 1988, I. i. 3). Asimismo, el primer libro del Novum Organum: "y justamente debe cerrarse aquí la parte destructiva de mi Instauración, que esta formada por tres refutaciones; a saber: refutación de la razón humana naturaldejada a sí misma; refutación de las demostraciones y refutación de las teorías o sistemas filosóficos y doctrinas admitidas [...] Por lo cual es hora de que pasemos al arte y a la norma misma de interpretar la naturaleza; todavía sin embargo queda algo que debe ponerse por delante. Pues habiéndome propuesto en este primer libro de los aforismos el dejar preparadas las mentes de los hombres tanto para entender como para recibir lo que sigue; ahora que he limpiado, rozado, y nivelado el suelo de la mente, viene ya el que la mente se coloque en posición propicia y como de buen talante frente a lo que voy a poner delante de ella" (Bacon, 2003b, I. cxv). 
se aleja de las academias; se despoja de la vestidura de docto y valora la filosofía desde la condición de hombre del común, lugar que le permite denunciarla por su esterilidad. En el siguiente nivel, deja su condición de hombre común y se ubica en la filosofía discutiendo aspectos epistemológicos. Allí situado, examina la relación que hay entre la utilidad y la verdad. En un tercer nivel, da un paso más y examina la relación que hay entre estos dos elementos con la moral. Allí, encuentra que una filosofía útil y verdadera es a la vez una filosofía guiada por la caridad y la humildad.

Hemos llamado niveles a estos análisis, puesto que el paso gradual de uno a otro conduce al trasfondo desde el cual Bacon levanta sus críticas y sus propuestas. El curso desde los signos externos hasta el ámbito moral es un curso que lleva desde lo que aparece en la superficie de la filosofía hasta lo que lo origina, hasta su causa. Por supuesto, es posible centrarse en sólo uno de tales niveles y comprender la filosofía baconiana desde allí; no obstante, hemos querido hilar unos con otros para encontrar que efectivamente los niveles se encuentran relacionados y que un estudio que indaga sobre la naturaleza del proyecto baconiano y su coherencia interna requiere mantenerlos enlazados.

Llevar el análisis de la crítica hasta el último nivel servirá para insistir en que la propuesta de Bacon trasciende los dominios de la mera producción de obras y artefactos, pero también de la epistemología. En sus obras de juventud, especialmente, la crítica moral devela no sólo el proceder de los filósofos, sino, también, a juicio de Bacon, la causa de la falsedad de la filosofía. Por este motivo, considerarla es de gran importancia para comprender el intento de reforma baconiano 9 .

\section{Crítica por los signos: la inutilidad de la filosofía}

Para adentrarnos propiamente en el contenido de la crítica de Bacon a la filosofía y a los filósofos, es necesario mencionar cómo o con qué medios la hace. Para examinar la filosofía, el autor propone dejar de ser filósofo por un momento:

9 Estamos de acuerdo con el énfasis que hace Benjamín Farrington (1971, pp. 155 y ss.) con respecto a la crítica de Bacon a la filosofía, en el sentido de que se trata de una crítica moral.
Desnudémonos, vosotros y yo, de nuestra condición de varones doctos, si algo de eso somos; hagámonos como unos del pueblo y, dejando a un lado las cosas mismas, admitamos conjeturas a partir de signos externos, pues al menos esto tenemos en común con los hombres (Bacon, 1985, p. 79).

El punto de partida es despojarse de la investidura de docto, esto es, dejar de lado los discursos típicos de los doctos, dejar por un momento la academia y sus argumentaciones ${ }^{10} \mathrm{y}$ situarse del lado del común de los hombres. Sin entrar en consideraciones sociológicas acerca de la expectativa que tenían los hombres del común del siglo XVII en Inglaterra sobre la filosofía, se puede afirmar que el vulgo aparece en los textos de Bacon como el lugar desde el cual se juzga la filosofía; con esto, Bacon rescata un interlocutor que quizás carecía de importancia en la tradición filosófica que Bacon critica.

De la misma manera, si bien diferentes estudios han señalado la importancia de otros saberes distintos a la filosofía en la formulación del proyecto baconiano, tales como la magia, la astrología, las artes mecánicas, la alquimia y la cultura retórica; y, en general, se suele decir que Bacon, como muchos de sus contemporáneos, intentó realzar el valor del saber operativo por encima del contemplativo11,

10 Como señala Stephen Menn (2003, p. 34), “la crítica a la filosofía en los siglos XVI y XVII se hizo primero por fuera de las academias y luego entró a ellas. Las nuevas filosofías se desarrollaron por fuera de las universidades, 0 al menos por fuera de las facultades de filosofía, y si ganaron un lugar en el currículo fue después de una larga lucha. La gente produjo una nueva filosofía porque había una demanda de una filosofía tal, esto es, una corriente a la expectativa de lo que la filosofía debía hacer, y un sentimiento de que la vieja filosofía no podía hacerlo propiamente. De hecho, uno puede decir que el legado que dejó la filosofía del siglo XVI al siglo XVII no fue una nueva filosofía particular sino justamente esta expectativa de una nueva filosofía".

11 Véase Rossi (1990, cap. 1). También Garin (1981, p. 201): “La gran deuda de Francis Bacon con las enseñanzas mágico-alquimistas emerge con claras transparencias en su modo de concebir la ciencia como poder, como obra activa que escucha el lenguaje de la naturaleza para apropiarse de él; para Bacon, la ciencia acabará por dominar la naturaleza y convertirla en su servicial esclava". De la misma manera, Serrano (2006, pp. 82-83): “Lo que se puede caracterizar teóricamente como el cambio del procedimiento deductivo, en el que la silogística aristotélica adquiere total hegemonía, al procedimiento inductivo que propone Bacon, se corresponde y parece estar íntimamente ligado al cambio que se sugiere de la antigua relación de dependencia entre el saber contemplativo y el operativo. Lo cual no quiere decir que se trate de un abandono de la 
no se podría afirmar que cuando Bacon decide despojarse de la vestidura de docto esté pensando en que la crítica a la filosofía debe hacerse desde estos otros lugares. En efecto, el vulgo es el lugar desde el cual se valoran los saberes -de allí que también estas otras artes caigan en las críticas- y es también el lugar al que los saberes retornan. Si bien Bacon retoma fines y modelos de las artes mecánicas, la magia y la alquimia, su propósito último es hacer que la filosofía llegue al hombre común y corriente "al que no se llega si no es por medio de lo útil y de las obras" (Bacon, 1985, p. 77). El hombre común se convierte en parte de la construcción de conocimiento, y se forma parte desde la posición de quien juzga dicha construcción. Así, el conocimiento comienza a romper sus fronteras y se abre a actores que antes no habían sido tenidos en cuenta. Bacon propone un conocimiento que no está centrado más en las discusiones de las academias ni en el saber de iluminados (magia y alquimia), sino que se hace público en la medida en que los hombres comunes lo valoran.

Por otro lado, situarse desde el hombre común implica que la filosofía será vista no a partir de sus cosas mismas, de sus tópicos internos, sino desde lo que ella muestra al exterior. Será valorada desde lo que ha dejado la filosofía a los hombres, más allá de largas discusiones y altercados. Como señala Paolo Rossi (1990, pp. 112-114): "Se trata de una valoración histórica de la filosofía, no de un análisis de los sistemas de pensamiento".

¿Qué ve el hombre común en la filosofía? Explícitamente Bacon no formula esta pregunta. No obstante, es posible reconstruirla y hallarle sentido desde sus textos. Al vulgo, en principio, no le

actitud contemplativa sin más, sino precisamente de una inversión de la relación: el saber contemplativo entra ahora a depender del saber práctico o contemplativo. Con eso se despeja otro posible malentendido que conduzca a la interpretación de Bacon como el representante de un saber meramente técnico carente de valor científico. En la medida en que Bacon busca las formas, está en una actitud contemplativa; en la medida en que las busca a partir de la experiencia, procede inductivamente; $y$ en la medida en que hace depender la forma buscada de su producción natural, reduce la verdad científica a operación efectiva y está en la actitud práctica". Para un análisis de la influencia de la retórica en Bacon puede consultarse: Gaukroger (2004, cap. 2) y del mismo autor (2006, pp. 129 y ss.). Un estudio acerca de cómo postula Bacon la elaboración de las historias naturales a la luz de los métodos humanistas véase: Blair (1992, pp. 541-551). interesa escudriñar en las cosas mismas, no le interesa bajo qué métodos procede la filosofía o cuáles son los asuntos que discute, pero sí ve de ella que en lugar de engendrar frutos, genera constantemente altercados y discusiones (Bacon, 1985, p. 77). Por eso, el primero de los signos -y en opinión de Bacon, el fundamental- es precisamente el que tiene que ver con la utilidad de la filosofía: "Así pues, retornemos ahora a examinar los sig $\neg$ nos. Ahora bien: ninguno de ellos es, hijos míos, más cierto o más notorio que el de los frutos" (Bacon, 1985, p. 125). Asunto que se mantiene en el Novum Organum: "entre los signos, ninguno hay más seguro y conocido que el que se deduce de los frutos" (Bacon, 2003b, I. lxxiii).

Si bien esta valoración de la filosofía es de gran importancia, pues, como insiste Rossi, muestra que existe un enlace entre la deficiencia del conocimiento y la situación histórica en las que éste ha estado inscrito ${ }^{12}$, es necesario señalar que esta vía es sólo la puerta de entrada a la crítica de la filosofía. Una indagación más profunda sobre los signos, en concreto sobre el signo fundamental, permitirá dar un paso más en la comprensión del proyecto baconiano. Ese paso es propiamente la relación entre la utilidad y la verdad por la cual se puede hallar que tal deficiencia es también resultado de un defecto en la concepción y el proceder de la filosofía natural. En esta otra situación se centra gran parte de la crítica baconiana.

\section{Crítica a la falta de verdad y a los procedimientos incorrectos}

Como señalábamos, el primero de los signos es precisamente el que tiene que ver con la utilidad de la filosofía. No obstante, cuando Bacon insiste en ésto, no está pensando meramente en producción de objetos o de resultados como fin último de la filosofía. En lugar de ello, considera que hay una íntima relación entre este signo y la idea de verdad, y que la utilidad debe ser buscada desde esa relación.

12 “En los Cogitata et visa y en la Redargutio philosopharum Bacon traza las grandes líneas de un panorama histórico que hace de la "culpa" de estos filósofos el resultado de una determinada situación histórica e identifica sus límites con los límites propios de una civilización" (Rossi, 1990, p. 114). Esto se sustenta en la insistencia de Bacon en que la antigüedad es en realidad la infancia del mundo, y en que el conocimiento del que se dispone en el siglo XVII supera ampliamente aquella otra edad. (Bacon, 1985, pp. 72-73 y 82-83). 
Hay que insistir en que no se trata de una búsqueda de la utilidad por ella misma, sino que la utilidad refleja el conocimiento verdadero. La utilidad es signo, precisamente, de la verdad de la filosofía: "las obras en sí mismas han de estimarse más en cuanto que son prendas de la verdad que por sus conveniencias para la vida" (Bacon, 2003b, I. cxxiv). De allí que los experimentos del investigador no deben conducir a este hacia la consecución inmediata de inventos; más bien, los experimentos preferidos son los que arrojan verdad, las experiencias lucíferas. Al referirse a ellas, Bacon muestra su distancia frente a la mera producción de resultados:

Pues el mecánico, sin preocupación alguna por verdad, no levanta su mente ni tiende su mano a cosa aluna que no esté subordinada a su trabajo. Más solamente habrá esperanzas bien fundadas de un progreso ulterior de las ciencias cuando se acepten y se reúnan en la historia natural muchos más experimentos que no son en sí de utilidad alguna y que se dirigen exclusivamente al descubrimiento de las causas y de los axiomas, a los cuales llamo yo lucíferos a diferencia de los fructíferos. Estos tales tienen en sí una virtud y condición admirable: a saber la de que nunca fallan ni se malogran. Pues siempre que se les emplee para esto, no para realizar algún trabajo particular sino para revelar la causa natural de alguna cosa, donde quiera que caigan, responden a su propósito, ya que deciden la cuestión (Bacon, 2003b, I. xcix).

El afán de utilidad guarda, entonces, estrecha relación con la búsqueda de la verdad. Por esto, su estudio debe hacerse en una reconstrucción epistemológica capaz de abordar dicha relación; esta sería, señala Pérez-Ramos, la tradición del principio verum factum, en la cual:

El factum apunta a la práctica en cuestión o a sus resultados: una acción intencional realizada en orden a alcanzar algún fin [...] El verum, de otro lado, introduce una pretensión de verdad en la primera dimensión, la cual, sin esta, sólo apuntaría a la utilidad o al placer (1998, p. 52).

Si bien el desarrollo extenso de este asunto es alcanzado en el Novum Organum - una vez Bacon describe en profundidad la idea de forma y el proceso de la inducción en relación a la utilidad-, en las obras que estudiamos ahora ya se encuentra presente esta idea. En la Refutación de la filosofía, obra marcada por la relación entre teología y filosofía, Bacon entiende la utilidad como el fruto de la verdad:

Pues del mismo modo que en la religión se procura mostrar la fe a partir de las obras, también eso mismo se traslada muy oportunamente a la filosofía, de suerte que sea vana la que es estéril. Y tanto más si en lugar de frutos como la uva o la aceituna produjera los cardos y las espinas de discusiones y contiendas (Bacon, 1985, p. 125)13.

Decir que la utilidad es un signo de la verdad implica que una filosofía que no es capaz de engendrar frutos, una filosofía estéril, es ella misma vana o falsa; por esto considera que la filosofía antigua y la filosofía en uso son falsas, más aún, teniendo en cuenta que estas filosofías sólo muestran al exterior altercados y discusiones. Pero, ¿puede decirse, a la inversa, que una filosofía que produce frutos es por ello verdadera? Bacon considera que esto no puede concluirse sin cierta cautela, pues la obtención de frutos puede ser resultado del azar y no de un proceso de búsqueda de la verdad conducido por un método correcto (Bacon, 1850b, p. 91). Aquí se encuentra, precisamente, el núcleo de las críticas a la alquimia, a la cual ataca porque sus resultados son fruto del azar y no de una práctica metódica14;

13 En el Novum Organum se señala: "los frutos y los inventos son como fiadores y garantes de la verdad de la teoría". La cita continúa: "Ahora bien, de toda la filosofía de los griegos y de las ciencias particulares que derivaron de ella, a duras penas se puede, después de un lapso de tantos años, aducir un solo experimento realmente aceptable que haya contribuido a aliviar y mejorar el estado del hombre, o que pueda aprovecharse para las especulaciones y dogmas de la filosofía [...] por lo cual, del mismo modo que en religión se nos previene y se nos recomienda que nuestra fe se eche a ver en nuestras obras, así pude aplicarse esto muy oportunamente a la filosofía juzgándola por sus frutos y dando por vana aquella que sea estéril: muy especialmente en el caso de que, en lugar de frutos de vid y de oliva, produzca cardos y espinas de disputas y contiendas" (Bacon, 2003b, I. Ixxiii). La misma idea se mantiene en Valerius Terminus: "Pero al contrario se puede concluir con seguridad que si esto no lleva a la ninguna invención, es vano $y$ falso" (Bacon, 1850b, p. 91).

14 "Y en lo que atañe a la práctica de los alquimistas, me parece que le viene como anillo al dedo aquella fábula del anciano que legó a sus hijos oro enterrado en una viña, sin que supieran con exactitud en qué lugar; al punto se pusieron a cavar la viña, y por cierto que del oro no encontraron nada, pero con esa labor la vendimia resultó más abundante. Del mismo modo, los hijos de la alquimia, al esforzarse en extraer trabajosamente el oro escondido-realmente 0 no-y en cierta manera enterrado en el huerto de la naturaleza, con sus muchas manipulaciones y ensayos, fueron de gran provecho y 
y a la magia natural, la cual, si bien ha enriquecido la práctica, lo ha hecho por medio de vanas conjeturas ${ }^{15}$. Unos y otros, unidos a los astrólogos, han alcanzado algunos frutos pero carecen de método. La idea de que la utilidad es un signo de la verdad de la filosofía se refuerza, entonces, al considerar que a Bacon no le interesa seguir las propuestas de aquellos que alcanzan frutos sin alcanzar verdad.

La verdad tendrá que emerger de un método de investigación correcto; sin un buen método no habrá esperanzas de que la filosofía cumpla su cometido: "Si los procedimientos para construir esta filosofía vuestra no son los debidos ni son aceptables, no sé qué esperanza os cabe abrigar, salvo que sea crédula y superficial" (Bacon, 1985, p. 139) ${ }^{16}$. De allí que Bacon llegue a afirmar en el Novum Organum que la raíz de los defectos de la ciencia puede encontrarse precisamente en la carencia de los auxilios adecuados ${ }^{17}$. Esto explica también el marcado énfasis que los intérpretes han dado a la epistemología baconiana.

Veamos, entonces, la crítica al método desde la perspectiva que estamos considerando. Hemos dicho que Bacon deja a un lado la magia y la alquimia, al considerar que allí no hay método como tal; justamente, su crítica es que obtienen resultados como resultado del azar. El método que Bacon critica con más fuerza es, entonces, el silogístico, pues

utilidad para los hombres, pues dotaron a la vida y a las actividades humanas de muchos inventos nada despreciables". (Bacon, 1985, p. 119). La misma idea se encuentra en (Bacon, 2003b, I. Ixxxv).

15 “ ¿De qué nos sirve, cuando sus dogmas son manifiestamente fantasía y superstición, y sus obras engaños e impostura?" (Bacon, 1985, p. 123). También: “Pero los cultivadores de la magia natural, que todo lo resuelven con simpatías y antipatías de las cosas, de conjeturas ociosas y negligentísimas dedujeron falsamente virtudes y operaciones maravillosas para las cosas y si bien a veces han producido obras, éstas son de tal índole que se presentan más bien a la admiración y a la novedad que al provecho y a la utilidad" (Bacon, 2003b, I. Ixxxv).

16 También: "si los hombres en el transcurso de tantos años se hubieran mantenido en el camino verdadero del descubrimiento y cultivo de las ciencias y a pesar de eso no hubieran podido avanzar más; audaz temeraria sin duda alguna hubiera sido la opinión de que el asunto pudiera llevarse más adelante. Pero si el error ha consistido en la vía misma y el esfuerzo del hombre se ha consumido en lo que no debía, síguese de ahí que la dificultad no nace de las cosas mismas, que no estan en nuestro poder, sino del entendimiento humano y de su uso y su aplicación; lo cual tiene remedio y medicina" (Bacon, 2003b, I. xciv).

17 “La causa y raiz única de casi todos los males de las ciencias es ésta: que mientras admiramos y enzalzamos sin razón las fuerzas de la mente humana, no le procuramos los auxilios apropiados" (Bacon, 2003b, I. ix). es éste el que se ha privilegiado en la investigación de la naturaleza ${ }^{18}$.

No es necesario ahondar en la crítica que ejerce Bacon al silogismo como forma lógica ni en las implicaciones ontológicas que esto conlleva, asuntos que han sido tratados por autores como Gonzalo Serrano y Antonio Pérez-Ramos en los textos que hemos citado. Nos interesa centrar la atención en la idea de anticipación de la naturaleza -idea que subyace a la construcción de saber por vía silogística, en tanto permite formular leyes generales-, pues es precisamente en la formulación de leyes generales en donde Bacon encuentra defectos tanto en el método en uso como en los filósofos ${ }^{19}$.

Bacon distingue entre anticipación e interpretación de la naturaleza (Bacon, 2003b, I. xix). Ambos métodos parten de la experiencia y buscan establecer axiomas generales, pero se diferencian en que el primero desde lo particular se remonta "en seguida" a los principios generales, mientras que el segundo se "eleva" prudente, paciente y reflexivamente. En la deducción silogística, señala, los principios o premisas generales (premisa mayor del silogismo) no han sido verificados, sino solamente admitidos o supuestos por los filósofos, son fruto de la anticipación de la naturaleza:

El silogismo consta de proposiciones, las proposiciones de palabras y éstas son símbolos de nociones. De modo que si las nociones mismas (que son la base de la realidad) son confusas y responden a una abstracción precipitada de los hechos, no puede haber solidez alguna en lo que se construye sobre ellas (Bacon, 2003b, I. xiv) ${ }^{20}$.

A estos principios supuestos se ha llegado por vía de la disputación, de la conjetura rápida y de la fe, más que por medio de la observación rigurosa de los procesos naturales, por eso fallan en su intento de captar la sutilidad de la naturaleza. Así, no son capaces de comprenderla, de interpretarla; solamente la anticipan.

18 Como muestra Kristeller (1970, pp. 195-196), la filosofía natural hunde sus raíces en el pensamiento aristotélico, más que en el pensamiento humanista del renacimiento.

19 Una exposición detallada de la diferencia entre anticipación e interpretación puede verse en Urbach (1993, pp. 25-58).

20 Este es un defecto de los escolásticos, más que del mismo Aristóteles, pues éste distinguía entre silogismo dialéctico y demostrativo (Serrano, 2006, p. 90). 
A juicio de Bacon, la mayoría de investigadores buscan con prisa acceder a los axiomas generales, pues esto les brinda tranquilidad y comodidad21; por ello, es necesario insistir en que tal elevación debe hacerse siguiendo un método riguroso: los investigadores necesitan más que plumas, plomo a la hora de postular las leyes generales22. El segundo libro del Novum Organum constituye, precisamente, los pasos por los cuales se da esta elevación prudente de la interpretación.

Con todo, Bacon ataca tanto a quienes piensan extraer obras de las mismas obras (los que tienen afán de utilidad sin reparar en la verdad) como a quienes dejan de lado la verificación de los principios de los cuales se deducen las obras (quienes proceden por anticipación). Habiendo caracterizado estos dos errores fundamentales de las filosofías podemos preguntar cuál era la filosofía que en la lectura de Bacon caía en ellos. Si bien este tópico está presente en otras obras, tanto en el Avance del saber como en el Novum Organum, Bacon intentó sistematizar los errores, o la vanidad, de los sistemas filosóficos que denuncia. En la obra de 1605, se refiere a dos tipos de vanidades: la que tiene que ver con las palabras y la que tiene que ver con la materia. A la primera pertenece el saber delicado, y a la segunda, el contencioso y el fantástico. Por saber delicado, saber de los retóricos, entiende aquel que

21 “El entendimiento humano, guiado guiado por las leyes de la dialéctica, sigue el mismo camino (entiendase el primero) que el que sigue cuando está abandonado a sus solas fuerzas. Pues la mente, con el afán de satisfacerse y tranquilizarse, tiene prisa por saltar a los principios más generales, y tras una breve dilación se hastía de la experiencia; y finalmente la dialéctica, con el aparato de las controversias, ha agravado estos males" (Bacon, 2003b, I. $\mathrm{xx})$. También, “El entidimento humano abandonado a si mismo en un espiritú prudente, paciente y serio, sobre todo sin la rémora de doctrinas aceptadas, intenta un poco aquel otro camino que es el recto, pero con poco provecho, ya que el entimiento si no se le rige y ayuda, es algo irregular y completamente inhábil para vencer la oscuridad de las cosas" (Bacon, 2003B, I. xxi). "Uno y otro camino tienen su punto de partida en los sentidos y en los hechos particulares y vienen a descansar en principios más generales: $\sin$ embargo, hay entre ellos una diferencia inmensa: mientras el uno toca apenas de pasada la experiencia y los hechos particulares, el otro se detiene sistemáticamente y ordenadamente en ellos; aquél establece desde el principio ciertas generalidades, abstractas e inútiles, mientras que el otro se eleva gradualmente a aquello que realmente es más conocido en el orden de la naturaleza" (Bacon, 2003b, I. xxii).

22 "Por lo tanto al humano intelecto no hay que pertrecharlo de plumas sino más bien de plomo y lastre que le contenga de todo salto y vuelo. Y esto no se ha hecho hasta ahora; más cuando se haga, se podrán tener mejores esperanzas de las ciencias" (Bacon, 2003b, l. civ). es condenado porque estudia las palabras y no las cosas, pues "las palabras no son sino imágenes de las cosas, y si éstas no están vivificadas por la razón y la invención, enamorarse de ellas es lo mismo que enamorarse de un cuadro" (Bacon, 1988, I. iv. 3). Este saber constituye un estorbo para la inquisición de la verdad y el progreso de la filosofía "porque satisface la mente humana demasiado pronto y apaga el deseo de ulterior indagación antes de alcanzado el término debido" (Bacon, 1988, I. iv. 4). Por saber contencioso, saber que prevaleció en los escolásticos, Bacon entiende: "aquel" que si bien abandona las palabras, no trabaja sobre la naturaleza sino sobre las mismas construcciones teóricas de los filósofos. $\mathrm{Al}$ alejarse de la evidencia de la naturaleza, estos filósofos no pueden engendrar frutos, sino dificultades y altercados en la medida en que avanzan en sus distinciones y conclusiones. Precisamente, señala Bacon, el hecho de que siempre estén discutiendo sobre altercados teóricos es señal de su extravío (Bacon, 1988, I. iv. 5). Finalmente, el saber fantástico es aquel concerniente al engaño o a la falsedad, en muchos casos, por permitir la mezcla entre filosofía y teología, por lo cual confunde el objeto de estudio (Bacon, 1988, I. iv, pp. 8-12).

Estas referencias muestran un panorama de las filosofías que Bacon quiere criticar. Ahora bien, no interesa en este momento hacer un empalme profundo entre la clasificación que presenta en la Refutación de la filosofía y la del Novum Organum ${ }^{23}$. Basta con decir que en la obra de 1620 desaparece la vanidad que tiene que ver con las palabras (el saber delicado), y en lugar de ello se centra únicamente en las que tienen que ver con la materia, es decir, aquellas que tienen pretensiones de alcanzar la verdad de la naturaleza. Las hemos traído a colación para

23 Por su parte, en el Novum Organum se refiere a la sofística, la filosofía empírica y a la supersticiosa. La sofística o llamada también racionalista, es acusada "pues se procura un montón de experimentos vulgares no debidamente comprobados ni examinados y pesados cuidadosamente, y deja lo demás a la contemplación y al ejercicio (agitatione) del ingenio" (Bacon, 2003b, I. Ixii). En la empírica, los filósofos "habiendo trabajado con mucha atención y cuidado en unos pocos experimentos se atrevieron por ello a deducir y planear sistemas filósoficos tergiversando de extraña manera el resto de los hechos conforme a aquellos" Ibíd. Finalmente, la filosofía supersticiosa es aquella en la que los filósofos “por religiosidad y respeto mezclan la ciencia con la teología y la tradición a algunos de los cuales los llevó hasta pretender sacar y derivar las ciencias de las inspiraciones de los genios y los espíritus; de modo que todo este linaje de errores y falsa filosofía es de tres clases: sofística, empírica y supersticiosa" Ibíd. 
mostrar que las vanas filosofías tienen errores comunes: la renuncia a la verdad y la falta de métodos. Por ello, Bacon ve necesario salir de este camino y emprender uno nuevo.

Pero, además de esto, nos interesa señalar que Bacon concibe la crítica a la filosofía al lado de la crítica a los filósofos. En este enlace, la filosofía vana indica, a la vez, vanos filósofos. Precisamente, la clasificación de los errores de la filosofía está precedida por esta anotación: "pues estimamos vanas aquellas cosas que son falsas o frívolas, aquellas en las que no hay verdad o utilidad; y estimamos vanas a aquellas personas que son crédulas o curiosas sin motivo" (Bacon, 1988, I. iv. 2)24. Los filósofos, tanto como la filosofía, están impregnados también de errores en su proceder, errores que la religión, la política, las academias y, en general, la tradición ha inculcado en las personas ${ }^{25}$. Este asunto es tema del siguiente apartado.

La utilidad como signo sirve a Bacon, entonces, para hacer una crítica a la filosofía desde una doble perspectiva: por un lado, a la filosofía griega y a sus seguidores por no engendrar ningún fruto. Por otro, sirve para denunciar a aquellos que logran producirlos, pero sin método alguno, es decir, que lo logran sin garantizar la verdad de la filosofía. Como se puede ver, la relación que ahora introduce entre utilidad y verdad hace que su lugar de la crítica no sea ya el común de los hombres. En efecto, si la verdad lleva a la utilidad o no es asunto de discusión de los filósofos. Como él mismo indica, la consideración de los signos obliga a entrar en la discusión sobre las cosas mismas (Bacon, 1985, p. 101), y sobre las cosas

24 En el Novum Organum, la crítica a la filosofía se trata de la doctrina de los ídolos, como ídolo del teatro. Esto es importante mencionarlo pues muestra que en las obras de juventud constituye una falta moral, pero en la obra de 1620 se convierte en una falta psicológica.

25 "Se han creado infinitos prejuicios; se han formado, recibido y esparcido infinitas opiniones. Los teólogos hicieron suyas muchas cosas procedentes de esa filosofía, y fundaron una cierta doctrina especulativa que es mezcla de las dos. Los políticos creyendo que va en beneficio de su reputación que se les tenga por doctos, salpican sus escritos y discursos con muchas cosas tomadas de dicha doctrina por todas partes. Incluso las expresiones y las palabras: hijos míos, están formadas a propósito con arreglo al dictamen de esa misma filosofía, siguiendo sus prescripciones y pareceres, hasta el extremo de que, al mismo tiempo, habéis aprendido a hablar, os fue necesario beber y empaparos de ésta - ¿diré feliz 0 infeliz?- cábala de errores. Y conste que ésta no solamente ha sido confirmada por consenso de individuos, sino también, en cierto modo, aprobada por acuerdos de academias, colegios, órdenes y hasta de gobiernos casi" (Bacon, 1985, pp. 75-76). mismas de la filosofía se discute propiamente con los filósofos. Utilizando el lenguaje de Bacon, diremos que el cambio de lugar de la crítica, lo cual implica un cambio de perspectiva, de lugar de enunciación y de interlocutores, es un signo que muestra que Bacon se halla aquí en otro nivel.

\section{Crítica moral: indagando la causa del error}

La crítica a los filósofos se conduce también siguiendo el esquema de la crítica a los fines y a los procedimientos. Pero el camino que toma aquí no lo lleva a considerar aspectos de carácter epistemológico. En lugar de ello, examina el camino moral que los filósofos han tomado. Esta crítica es de suma importancia, porque en ella cree Bacon encontrar causas de los errores filosóficos. Intentaremos mostrar, entonces, que para Bacon el error de la filosofía no es sólo un asunto que atañe a la definición de nuevos fines y método, sino que este tiene a la base una nueva actitud moral ante el conocimiento y la historia. Con este giro dejamos a un lado el nivel del análisis epistemológico sobre la filosofía y pasamos a otro nivel en el cual éste se funda: el análisis moral. Bacon lleva su crítica hacia dos virtudes cristianas: la caridad y la humildad, y las relaciona con los fines y procedimientos de la filosofía.

\section{Caridad}

Retornemos a la primera crítica, la inutilidad de la filosofía. En términos generales, como se ha visto, Bacon acusa a los filósofos antiguos de profesar una filosofía estéril. Entre ellos, quizás sea Aristóteles quien más es criticado por Bacon, al considerar que es él "el principal causante de este mal" (Bacon, 1985, p. 127). Después de Aristóteles, la crítica a los filósofos se centra en Platón, y con ellos dos se extiende a los demás (Pitágoras, Empédocles, Heráclito, Anaxágoras, Demócrito, Parménides y otros, Bacon, 1985, p. 101) bajo el supuesto de que todos "eran semejantes, pues la filosofía de los griegos es a modo de una única nave: siendo diversos los errores, son comunes sus causas" (Bacon, 1985, p. 105).

El enlace encontrado entre utilidad y verdad introduce a Bacon en la crítica a Aristóteles. Éste promulga una filosofía que fue seguida por los escolásticos, en la que "no parece buscarse el descubrimiento de la verdad sino el fomento de la discusión" (Bacon, 1985, p. 129). El esquema de estudio natural aristotélico cae también bajo acusación, 
tanto por la presentación de la ciencia en forma de cuestiones como por la forma de las soluciones que da: "el principal empeño de Aristóteles fue que los hombres tuviesen preparado, en cada caso, qué decir, qué responder y por dónde escabullirse, con preferencia a qué debían creer profundamente, o pensar con claridad, o saber de verdad" (Bacon, 1985, pp. 128-129).

Pero, a medida que Bacon se adentra en la acusación a Aristóteles, va abandonando el terreno epistemológico y se instala en el de las virtudes que, a juicio de Bacon, llevaron al estagirita a plantear su esquema filosófico. Aristóteles:

Viene en nombre propio, ése es Aristóteles, que en todo se tiene a sí mismo por la autoridad, y que de tal modo despreció a los antiguos que casi ni se digna nombrar a ninguno de ellos, como no sea para refutarlo e injuriarlo (Bacon, 1985, p. 95).

Aristóteles, en opinión del autor, aunque diga representar la verdad, no habla en su nombre, sino a título personal; por eso requiere acallar a los demás filósofos. En esto radica su impostura. La actitud frente a las demás filosofías soporta esta acusación: "a la manera de los turcos, creyó que no podría reinar sin haber exterminado a sus hermanos. Cosa que le salió según sus deseos, y con demasiado éxito, no en el momento pero sí más tarde" (Bacon, 1985, p. 95). En suma, Bacon está acusando a Aristóteles de querer imponerse sobre los demás. Esto es, en lugar de buscar el beneficio del hombre, buscó el dominio sobre los demás, en ello radica su vanidad.

La vanidad de Aristóteles, el principal causante de la esterilidad de la filosofía, radica en desear más que el avance del saber, su prestigio frente a los demás hombres y frente a la historia. Aristóteles, pues, es acusado de encarnar la ambición más baja: querer imponerse sobre los demás.

Además no estará fuera de lugar el distinguir tres géneros y como si dijéramos tres grados de ambición de los hombres. El primero es el de aquellos que anhelan extender su propio poder en su patria; que es un género vulgar y bajo. El segundo, es el de aquellos que se esfuerzan por aumentar el poderío e imperio de su patria entre el genero humano; el cual tiene ciertamente más dignidad, aunque no menos concupiscencia. Más si alguien del género humano se esfuerza por instaurar y acrecentar el poderío e imperio de éste sobre el universo, esa ambición (si así puede llamársela) es sin duda no sólo más sana, sino también más noble que las demás. Ahora bien, el imperio del hombre sobre las cosas reside por entero en las artes y las ciencias. Pues no se manda a la naturaleza sino obedeciéndola (Bacon, 2003b, I. cxxix).

Como Bacon lo presenta en esta cita, el deseo de una nación de imponerse sobre otras también es censurado en relación con el fin último del conocimiento, el cual es proveer frutos a la especie humana. Por ello, Bacon considera que los hombres que sólo buscan favorecer a un estado determinado no merecen un premio superior a quienes buscan el beneficio de la especie humana ${ }^{26}$. La razón de esto es doble: por un lado, los bienes de los primeros son pasajeros, pues están circunscritos a la valoración que de ellos hace una nación en un momento determinado, mientras que los segundos son permanentes y universales; por otro, los primeros surgen de luchas y altercados, los segundos de la presencia divina.

Así, ni Aristóteles, en el plano particular; ni Alejandro, su sucesor, en el plano civil, son para Bacon el modelo a seguir: "conquistando uno todas las opiniones como el otro conquistó todas la naciones" (Bacon, 1988, II. vii., p. 2), pues sus ambiciones son todavía censurables al lado de la mayor aspiración del hombre y el conocimiento. Ninguno de los dos es acusado de falta de ingenio o de saber, pero son acusados de errar en su ambición. Para Bacon, pues, el modelo no está en ninguno de ellos, sino en quien es capaz de trabajar no por su propio beneficio y el

26 Legisladores, fundadores y unificadores de estados y ciudades, padres de la patria y otras figuras, "eminentes en lo civil no eran honrados sino con el título de héroe o semidiós, [...] en cambio los inventores y autores de nuevas artes, bienes y mejoras para la vida humana eran siempre incluidos entre los propios dioses" (Bacon, 1988, I. vii. 1). Véase también: "The dignity of this end, of endowment of man' life with new commodities, appeareth by the estimation that antiquity made of such as guided thereunto; for whereas founders of states, law-givers, extirpers of tyrants, fathers of the people, were honoured but with the titles of worthies or demigods, inventors were ever consecrated amongst the gods themselves. And if the ordinary ambitions of men lead them to seek the amplification of their own power in their countries, and a better ambition than that hath moved men to seek the amplification of the power of their own countries amongst other nations: better again and more worthy must that aspiring be, which seeketh the amplification of the power and kingdom of mankind over the world: the rather, because the other two prosecutions are ever culpable of much perturbation and injustice; but this is a work truly divine, which cometh "in aura leni," without noise or observation" (Bacon, 1850b, p. 84). 
de su nación, sino por el de dar dominio sobre la naturaleza a la especie humana en general.

Bacon no propone el avance del saber sin más, sino un avance que se encamine al provecho humano. Pero en este nivel, el provecho de la filosofía no es una mera utilidad exigida por el hombre común, sino una exigencia moral que revela un trasfondo religioso: "Si yo hablara con las lenguas de los hombres y de los ángeles, y no tuviera caridad, sería como címbalo que resuena"; seguidamente, Bacon cifra en la caridad la razón de esto:

No porque el hablar con las lenguas de los hombres y de los ángeles no sea cosa excelente, sino porque, si se separa de la caridad y no se aplica al bien de los hombres y de la humanidad, es más gloria resonante e indigna que virtud meritoria y sustancial (Bacon, 1988, I. i. 3)27.

Esa otra ambición, a la cual Bacon llama caridad, debe ser la única ambición del conocimiento, "si es que se le puede dar tal título”, por encima del poderío en el mismo país, y del poderío del país sobre los otros países.

Con todo, la escala de ambición se teje entre el beneficio personal y el beneficio de la especie: entre la impostura y la caridad; la primera tiende a mostrarse como la segunda, de allí que se le llame precisamente "impostura"; la segunda muestra sus signos en el provecho humano. Aristóteles encarna el nivel más bajo en la escala, y la nueva filosofía que propone Bacon encarnaría su polo opuesto. En medio de esa escala, se encontraría el afán por el beneficio de los estados.

Ahora bien, Bacon introduce la caridad en la filosofía a modo de correctivo. Ya nos referimos a la caridad como correctivo de los fines del conocimiento; ahora haremos una alusión en cuanto correctivo que delimita el campo de estudio. Lo que ha hecho al conocimiento perder su rumbo no es, señala Bacon, su misma naturaleza, sino tomarlo sin el debido correctivo; de allí que se requiera ayudas para conducir el conocimiento: "Esa especia correctiva, cuya adición hace al conocimiento tan soberano, es la caridad, que el apóstol agrega in $\neg$ mediatamente a

27 Véase también: “Finalmente, quiero advertir a todos los hombres en general, que mediten en los verdaderos fines de la ciencia, $y$ no se dirijan a ella por gusto ni para disensiones, ni con el fin de despreciar a otros ni para su bienestar o su fama o su poder 0 bajezas semejantes sino para rendimiento y utilidad de la vida; y que la perfeccionen y gobiernen en caridad" (Bacon, 2003a, p. 51). la cláusula citada, pues dice: El conocimiento hincha, pero la caridad construye" (Bacon, 1988, I. i., p. 3). Bacon es consciente de que la búsqueda de conocimiento sin correctivo conduce a la vanidad, por eso, en sus obras recuerda la necesidad de ponerle límites (Bacon, 1988, I. i., p. 3), ya sea por vía de la religión ${ }^{28}$ o por el recto uso de la razón ${ }^{29}$; límites que, en todo caso, refieren al correctivo de la caridad. Indaguemos un momento en ellos.

En el Avance del saber señala estos límites. Nos interesa tratar el que tiene que ver con la separación entre filosofía y teología. Bacon entiende la búsqueda de las causas formal y final como parte de la metafísica, a diferencia de la física, la cual se ocupa de la eficiente y material (Bacon, 1988, II. vii., p. 4); no obstante, ambas hacen parte de la filosofía natural, esto es, de la filosofía a la cual se llega por la luz de la razón. Pero mientras la causa final lleva a considerar la intención, la formal lleva a la generación de obras -en la cual la pregunta por la intención no tiene cabida-, por eso la filosofía natural se dedica sólo a esta última. Bacon, a diferencia de Platón, entiende que mantenerse en la causa formal es permanecer en la materia, es decir, en la naturaleza, única posibilidad de encontrar las formas o normas para la operación. Aquí es necesario volver sobre aquella idea de que la utilidad es caución de la verdad, pues Bacon considera que la utilidad es el reflejo de que se está auscultando la forma y no otras causas de la naturaleza ${ }^{30}$. Así, la filosofía encuentra un límite en tanto debe entenderse ella misma como contemplación de las obras de Dios y no de la naturaleza o voluntad divina. Precisamente, aquí radica la separación que Bacon quiere hacer entre filosofía y teología, con lo cual logra la autonomía de la filosofía 31 .

28 "I thought it good and necessary in the first place, to make a strong and sound head or bank to rule and guide the course of the waters; by setting down this position or firmament, namely, "That all knowledge is to be limited by religion, and to be referred to use and action" (Bacon, 1850b, p. 81).

29 "Recobre ahora el género humano su derecho sobre la naturaleza, el que le compete por el legado divino, y désele poder: la recta razón y una religión sana regirán su ejercicio" (Bacon, 2003b, I. cxxix).

30 "Más si se mantienen una vigilancia continua y una mirada severa sobre la acción, operación y empleo del conocimiento, será posible advertir lo que son las formas" (Bacon, 1988, II. vii. 5).

31 Como lo muestra Gaukroger (2004, p. 95; 2006, p. 115 y ss., 157 y ss.), la filosofía logra su autonomía en un proceso que se inicia en el siglo XIII y que se consolida en el siglo XVII. Bacon se inscribe en esta empresa precisamente en su intento de separar los objetos de estudio de ambas disciplinas. También véase Reale y Antiseri. 
Por medio de esta limitación, Bacon quiere mostrar que, si bien hay una demarcación que aparta el estudio filosófico de la teología y de la religión, el correctivo moral sí afecta el campo epistemológico. Con todo, Bacon no considera que los valores estén separados de la investigación de la filosofía natural. Las consideraciones morales, además de servir para la organización de colectivos investigativos y para definir los propósitos de la investigación, las tiene en cuenta Bacon para indicar las cosas mismas por las que debe guiarse la filosofía: la búsqueda de las formas y el método inductivo.

Siguiendo una constante en la filosofía de los siglos XVI y XVII, Aristóteles es el centro de la crítica de Bacon. Ampliamente ha sido estudiada su crítica al silogismo, pero en este caso se trata de una crítica moral en la cual el filósofo griego pierde protagonismo al ser fijado en el nivel moral más bajo por encarnar la ambición más baja. Bien podría pensarse que la crítica moral a Aristóteles no tiene relación necesaria con la filosofía de Aristóteles. No obstante, como Bacon comprende aquí el desarrollo filosófico, la actitud moral es de alguna manera una causa del error filosófico, pues el propósito que persigue un filósofo delimita así mismo el camino que sigue y los métodos por los cuales se conduce. Veamos esta idea en la crítica al método.

\section{Humildad}

Retornemos a la cita en que se hablaba de las ambiciones: "Ahora bien, el imperio del hombre sobre las cosas reside por entero en las artes y las ciencias. Pues no se manda a la naturaleza sino obedeciéndola”. Aquí se muestra algo que ya antes habíamos anunciado: la unión entre el fin del conocimiento y el método de la filosofía; unión que en los términos de la crítica moral se traduce en aquella entre caridad y humildad. En efecto, Aristóteles no sólo es acusado de falta de caridad, esto es, de confundir el fin del conocimiento. A partir del examen de su filosofía natural es acusado de soberbia32. En último

(1988, tomo II, cap. IV-VI), y Mínguez (2006, pp. 122-140). Cabe recordar también que ante el rechazo a Aristóteles, y la necesidad de encontrar un nuevo enlace entre el pensamiento filosófico griego y el pensamiento cristiano, Agustín se alza como una figura que puede mostrar ese camino. Así, el intento de lograr autonomía para la filosofía tiene un trasfondo agustiniano en la doctrina de la separación entre luz natural y luz divina. Para este asunto véase Gaukroger (2004, p. 79 y ss.). También, Menn (2003, pp. 42-44).

32 "Ponemos a vuestra memoria por testigo, hijos míos, de si en sus libros físicos y metafísicos no oís más a menudo las voces de la dialéctica que las de la naturaleza" (Bacon, 1985, p. 89). término, dejar de auscultar la naturaleza para imponerle categorías propias es reflejo de la soberbia humana: "la soberbia empuja a los hombres hasta tales extremos de locura que no auscultan el latido de la naturaleza sino su propio latir, y aunque crearan artes para auscultarlo, no darían con él" (Bacon, 1985, p. 115).

La acusación a los escolásticos, y en general al saber contencioso, se mantiene en esta misma línea:

Así como en la inquisición de la verdad divina su soberbia los inclinó a abandonar el oráculo de las obras de Dios y a disiparse en la mixtura de sus invenciones propias, así también en la inquisición de la naturaleza abandonaron el oráculo de las obras de Dios y adoraron las imágenes engañosas y deformadas que el espejo desigual de sus propias mentes, o de unos cuantos autores o principios prestigiosos, les presentaban (Bacon, 1988, I. iv., p. 7) $)^{33}$.

La soberbia quiere decir aquí imponer categorías a la naturaleza; su contrario, la humildad, indica dejarla hablar. Dejarla hablar quiere decir propiamente "obedecerla", pues sólo escuchándola se pueden encontrar sus leyes ${ }^{34}$. Por vía de la humildad, el filósofo puede hacerse propiamente sirviente e intérprete de la naturaleza 35 . De esta manera, anticipación e

33 Véase también: “The felicity wherewith he hath blessed an humility of mind, such as rather laboureth to spell, and so by degrees to read in the volumes of his creatures, than to solicit and urge, and as it were to invocate a man's own spirit to divine, and give oracles unto him. For as in the inquiry of divine truth, the pride of man hath ever inclined to leave the oracles of God's word, and to vanish in the mixture of their own inventions; so in the selfsame manner, in inquisition of nature, they have ever left the oracles of God's works, and adored the deceiving and deformed imagery, which the unequal mirrors of their own minds have represented unto them. Nay, it is a point fit and necessary in the front, and beginning of this work, without hesitation or reservation to be professed, that it is no less true in this human kingdom of knowledge, than in God's kingdom of heaven, that no man shall enter into it, "except he become first as a little child" (Bacon, 1850b, p. 84).

34 “Ciencia y poder humanos coinciden en una misma cosa, puesto que la ignorancia de la causa defrauda el efecto. A la naturaleza no se la vence sino obedeciéndola, y lo que en la observación es como causa, es como regla en la práctica" (Bacon, 2003b, I. iii).

35 “Pues el hombre, servidor e intérprete de la naturaleza, hace y entiende tanto cuanto observare acerca del orden de la misma, con sus obras o con su mente: ni sabe ni puede más. Pues ni habrá fuerza alguna que pueda romper o soltar la cadena de las causas; ni la naturaleza se vence de otro modo que obedeciendo" (Bacon, 2003a, p. 65). 
interpretación de la naturaleza quedan relacionadas estrechamente con soberbia y humildad, respectivamente.

En efecto, Bacon aquí está pensando que cualquier método que se derive de la soberbia es, desde su misma raíz, un método errado para captar la naturaleza. Es esto lo que ocurre a Aristóteles y a los escolásticos, pues su afán de imponerse frente a la naturaleza y frente a los demás los condujo a desarrollar una red de conceptos que, antes que permitir captar la naturaleza, impone categorías sobre ella, razón por la cual es inevitable que ésta se le escape. En este punto, se puede comprender que la animadversión al silogismo está no sólo en estrecha relación con la concepción del saber y con su actitud frente a la naturaleza ${ }^{36}$, sino, también, con su posición moral frente a la filosofía.

Bacon subraya tres diferencias de su propuesta frente a la antigua lógica: el fin que se propone, el punto de partida y el orden de la demostración. Ya nos hemos referido, y más adelante insistiremos en ello, al propósito de la filosofía: en la propuesta baconiana, la caridad. Para invertir el punto de partida, esto es, para hacer un examen de las nociones generales desde las cuales se dan explicaciones sobre la naturaleza, es necesario dejarla hablar, callar; es necesaria la humildad. Mientras el filósofo no calle para auscultar el latir de la naturaleza, la sutilidad de ésta será mayor que la de sus construcciones teóricas. Finalmente, la estructura silogística-deductiva, como demostración de la antigua lógica, no aporta para salir del error al que lleva la soberbia, pues el silogismo se erige sobre las nociones generales ya aceptadas.

De la misma manera, se puede comprender la carga moral que tiene la inducción: si el filósofo está en actitud de escuchar, entonces puede captar los principios naturales, en la recolección de experiencias por medio de las distintas tablas y en su posterior proceso de registro y escritura. Este intento de no imponer categorías a la naturaleza, ni siquiera en la observación, lleva a Bacon a proponer que en las tablas por las que se construye el conocimiento deben registrarse experiencias de todo tipo, incluso aquellas que a primera vista parecen inútiles o no importantes para la investigación.

36 El trabajo de Serrano (2006, p. 35) muestra esta relación. Nos interesa mostrar la relación que tiene esa animadversión con la perspectiva moral baconiana.
Dejemos a un lado la crítica a Aristóteles y veamos cómo se refiere a Platón. Él es atacado fundamentalmente por ir en pos de acrecentar su fama por medio de la filosofía, por haber mezclado filosofía y teología ${ }^{37}$ y por haber introducido la acatalepsia ${ }^{38}$. No nos referiremos a la primera crítica, pues bien se puede entrever que la ambición de fama indica que Platón está por fuera del camino del conocimiento verdadero y caritativo, de aquel que busca no el provecho propio, sino el beneficio del género humano. Por su parte, la mezcla entre teología y filosofía resulta de singular importancia, no sólo porque muestra los límites morales del filósofo, sino porque distinguirlas ayuda a Bacon a delimitar el objeto propio de estudio la filosofía. Aspecto al que ya nos referimos anteriormente.

Nos detendremos en la acusación que le hace de haber introducido la acatalepsia. Ésta la entiende Bacon como el exceso contrario al estudiado con Aristóteles39: en lugar de imponer categorías a la naturaleza, la acatalepsia afirma la imposibilidad de conocerla precisamente porque escapa de las manos por su sutilidad 40 . ¿Cómo se entiende la

37 “No se preocupó gran cosa por la filosofía natural, salvo en la medida indispensable para defender su nombre y su fama de filósofo, así como para añadir e infundir cierta grandeza a sus doctrinas morales y políticas. De ahí que cuanto escribió sobre la naturaleza no goce de solidez alguna. Es más: envenenó y corrompió la naturaleza, con teología, no menos que lo hizo Aristóteles con dialéctica" (Bacon, 1985, pp. 99-100).

38 “La escuela de Platón, por su parte, introdujo la acatalepsia, al principio como en broma y por ironía por aversión a los antiguos sofistas: Protágoras, Hipias y demás, que de nada parecían asustarse tanto como de parecer que tuvieran dudas de cosa alguna. Pero la Nueva Academia dogmatizó la acatalepsia e hizo de ella un principio" (Bacon, 2003b, I. Ixvii).

39 "Y este exceso es de dos clases: el primero es el de aquellos que se pronuncian fácilmente y hacen a las ciencias, positivas y magistrales; el otro, el de los que introdujeron la acatalepsia y la inquisición vaga y sin objeto; de los cuales el primero deprime el intelecto y el segundo lo enerva" (Bacon, 2003B, I. Ixvii).

40 "Pues ellos, que con tanta confianza dictaminan acerca de las cosas, a intervalos, cuando recapacitan consigo mismos, empiezan a quejarse de la sutilidad de la naturaleza, de la oscuridad de las cosas y de la flaqueza del ingenio humano. Esto si lo hiciesen sencillamente, podría acaso apartar a algunos más tímidos de toda inquisición posterior, pero en cambio incitaría y estimularía a otros, de temperamento más animoso y confiado, a progresar en la investigación. Pero no les basta con confesar esto de sí mismos sino que de todo aquello que está fuera de su conocimiento y alcance o el de sus maestros, lo colocan fuera de los límites de toda posibilidad y como apoyados en razones científicas lo declaran imposible de hacerse o de conocerse. Soberbia y malicia extremas, servirse de la inconsistencia de sus invenciones para calumniar a la naturaleza y desesperar a todos los demás" (Bacon, 2003b, I. Ixxv). Véase también: "Tenemos también otro signo, si es que esa denominación conviene a este caso, ya que es más bien testimonio, incluso el más 
acatalepsia en la crítica moral? Tendería a pensarse que si la imposición de categorías es fruto de la soberbia, la acatalepsia es un reconocimiento que parte de la humildad del saber. Más para Bacon esto no es así; todo lo contrario, es también un exceso de soberbia:

Pues lo que pretenden con todas sus fuerzas es poner y desplazar fuera de los límites de lo posible, todo aquello que en las ciencias fuese desconocido o no tratado por ellos mismos o sus maestros: ésta es su modestia y humildad (Bacon, 1985, p. 137).

La acatalepsia la entiende Bacon como el intento de poner límites al conocimiento justo donde terminan las posibilidades de conocer de quien la promulga; ella condena al conocimiento a quedar encerrado en lo que algún autor ha alcanzado. Quienes la promulgan convierten su debilidad en calumnia a la naturaleza y al conocimiento (Bacon, 1985, p. 137)41. Así pues, tampoco ellos son, efectivamente, verdaderos sirvientes de la naturaleza; tampoco la acatalepsia refleja la "fecundidad de la humildad".

Hemos intentado mostrar que la crítica de Bacon a la filosofía se lleva a cabo en distintos niveles, a partir de los cuales se han ido acuñando conceptos clave para desarrollarla. La crítica la hemos llevado hasta el nivel en el que Bacon pretende encontrar las causas de la vanidad de la filosofía hasta el nivel moral; por tanto, podemos afirmar que Bacon no entiende este nivel como un nivel externo o añadido a su proyecto científico. Es enfático al señalar que su reforma epistemológica debe estar dirigida por la caridad y la humildad, aspectos que no serían

sólido de todos los testimonios. Se trata de la propia confesión y juicio de los autores en los que habéis depositado vuestra confianza. En efecto: los mismos que impusieron una cierta dictadura en las ciencias y con tanta seguridad se pronuncian sobre las cosas, a ratos, sin embargo, cuando recapacitan, se entregan justamente a lamentarse de la sutilidad de la naturaleza, la oscuridad de las cosas, la debilidad del ingenio humano y de cosas parecidas" (Bacon, 1985, p. 135).

41 Véase también: "Pues primeramente se encuentra aquella treta y ardid ya conocido y familiar, común a todas las artes, esto es, que las autoridades en cualquier arte conecten en calumnia contra la naturaleza la debilidad de su arte; y lo que su arte no alcanza lo declaran en nombre de su mismo arte, imposible por naturaleza" (Bacon, 2003b, I. Ixxxviii). tomados en cuenta cuando se quiere estudiar exclusivamente los aspectos epistemológicos de sus planteamientos. En efecto, si bien es posible interpretar y examinar la obra de Bacon tomando por referencia dominios específicos, como el ético, el político, el epistemológico, el ontológico, entre otros, no parece ser el caso que el autor inglés desarrolle su reforma sin tener en cuenta las relaciones que hay entre ellos.

Como se mostraba en el primer apartado, Bacon levanta su crítica a partir de la valoración histórica de la filosofía, en la cual encontraba que ésta no ha dado frutos al hombre común, que ha sido inútil. En este nivel, fija también el cometido filosófico: la utilidad. A partir de las críticas al saber de su tiempo, en el segundo apartado se mostraba que la inutilidad está ligada a la falta de verdad y de método; aspectos concernientes a la discusión epistemológica, ya no a la histórica. Opuesto a ello, en consideración de Bacon, la utilidad es signo de la verdad y la utilización de los auxilios adecuados. Finalmente, en el tercer apartado se mostraba que la renuncia a la verdad se apoya en un afán de dominio de los hombres sobre los hombres mismos, y que la falta de método está relacionada con el impulso de alcanzar verdades rápidamente imponiendo a la naturaleza categorías del investigador (soberbia). Aspectos concernientes al análisis moral. En la transformación que Bacon propone se requiere, pues, afán de servicio al hombre y (caridad) y virtud para dejar que la naturaleza hable por sí misma (humildad).

La tabla 1 reúne, entonces, los conceptos sobre los cuales transita Bacon:

Tabla 1. Conceptos clave de Bacon.

\begin{tabular}{|l|l|l|}
\hline & \multicolumn{1}{|c|}{$\begin{array}{c}\text { Camino } \\
\text { errado }\end{array}$} & \multicolumn{1}{|c|}{$\begin{array}{c}\text { Camino } \\
\text { correcto }\end{array}$} \\
\hline Nivel histórico & Inutilidad & Utilidad \\
\hline $\begin{array}{l}\text { Nivel } \\
\text { epistemológico }\end{array}$ & $\begin{array}{l}\text { Vanidad } \\
\text { y anticipación } \\
\text { (inducción } \\
\text { incorrecta) }\end{array}$ & $\begin{array}{l}\text { Verdad } \\
\text { e interpretación } \\
\text { (legítima } \\
\text { inducción) }\end{array}$ \\
\hline Nivel moral & $\begin{array}{l}\text { Ambición y } \\
\text { soberbia }\end{array}$ & $\begin{array}{l}\text { Caridad y } \\
\text { humildad }\end{array}$ \\
\hline
\end{tabular}


A nuestro juicio, el enlace entre estos niveles -y sus conceptos- previene de acusaciones que se han hecho a Bacon. En efecto, si se olvida que la propuesta busca un desarrollo moral de la filosofía y los filósofos, se interpretaría su aporte como restringido al campo epistemológico y rápidamente caería en olvido, al notarse las fallas en su estructura, o se pensaría que se trata de un tecnicismo moralmente neutro. Por otro lado, si se olvida que detrás de su proyecto hay también una búsqueda de la verdad, fácilmente se le puede acusar de construir una ciencia para ingenieros o se afirmaría que se trata de un mero utilitarismo. Por eso, a nuestro juicio las dos perspectivas -la epistemológica y la moral- deben estar enlazadas para comprender los alcances del proyecto baconiano. Ninguna, tomada aisladamente, daría cuenta de ello.

Por otro lado, al indagar sobre las exigencias morales que Bacon da a su proyecto, nos encontramos con la disputa entre si se trata de una propuesta que busca el desarrollo e imperio de la monarquía inglesa o si tiene como panorama el beneficio de la especie en general. Como vimos, Bacon piensa en esta última opción y rechaza tajantemente la primera. Al pensar en términos de la especie, y no en términos de un solo pueblo, en la propuesta de Bacon, el hombre se ubica frente a la naturaleza e intenta recobrar su posición frente a ella -aspectos que desarrollará en los escritos de corte teológicofilosófico, también en las obras de juventud. Si bien es conciente de que el avance del saber puede llevar a reorganizaciones políticas, no aparece un hombre frente a los demás o un pueblo frente a los demás como propósito moral o antropológico. Bacon prefiere un dominio del hombre sobre la naturaleza al dominio del hombre sobre el hombre y cree encontrar en la nueva filosofía un camino para lograrlo.

\section{Bibliografía}

Bacon, F. (1850a). Essays. En The works of Francis Bacon, Lord Chancellor of England (pp. 11- 67). Philadelphia: A Hart, Late Carey y Hart.

Bacon, F. (1850b). Valerius Terminus. En The Works of Francis Bacon, Lord Chancellor of England (pp. 8196). Philadelphia: A Hart, Late Carey y Hart.

Bacon, F. (1988). El avance del saber. Madrid: Alianza.

Bacon, F. (2003a). Instauratio Magna. Buenos Aires: Losada.
No obstante, si bien es cierto que en el terreno de la puesta en práctica no resulta fácil determinar en qué situaciones cierto conocimiento favorecerá a unos o a otros, o incluso tomar una decisión ante la alternativa de tener que favorecer a unos frente a otros, $o$ ante la imposibilidad de lograr un beneficio para todos. En todo caso el filósofo natural debe despojarse de sus ambiciones personales y grupales para pensar estos asuntos en términos de beneficio de la especie. Bacon no desarrolla a profundidad cómo se ejerce este correctivo de la caridad a la hora de ponerlo en práctica; no obstante, el principio de imperio humano se postula como regla última del desarrollo de la ciencia. Al menos este correctivo permite pensar que la ciencia no debe ordenarse a fines personales o políticos.

Si se prescinde de este trasfondo, es fácil caer en la idea de Bacon que propone un conocimiento y un dominio ilimitados del hombre sobre la naturaleza. Los límites que impone la caridad previenen de la utilización del conocimiento para fines de dominio social o político y podría prevenir de tomar a la naturaleza como una "estación de gasolina", como diría Heidegger. En efecto, la idea de beneficio para la especie serviría de correctivo ante excesos de devastación natural.

Es necesario revalorar el aporte de Bacon tanto en la transformación del pensamiento del siglo XVII como en el desarrollo del pensamiento en los siglos posteriores, a partir del estudio de las conexiones conceptuales entre el dominio epistemológico y otros dominios, pues resulta poco esclarecedor decir que el valor de la obra de Bacon se restringe al planteamiento de un nuevo método.

Bacon, F. (2003b). Novum Organum. Buenos Aires: Losada.

Bacon, F. (1985) Refutación de la filosofías. Madrid: Consejo superior de Investigaciones Científicas.

Blair, A. (1992). Humanist methods in natural philosophy: the commonplace book. Journal of the History of Ideas, 53, 541-551.

Box, I. (1999). Bacon's moral philosophy. En M. Peltonen (ed.), The Cambridge companion to Bacon (pp. 260282). Cambridge: Cambridge University Press. 
Channing Brings, J. (1999). Bacon's science and religion. En M. Peltonen (ed.), The Cambridge companion to Bacon (pp. 173-199). Cambridge: Cambridge University Press.

Farrington, B. (1971). Francis Bacon: filósofo de la revolución industrial. Madrid: Ayuso.

Frondizi, R. (2003). Significado y contenido del Novum Organum. En Novum Organum (pp. 7-36). Buenos aires: Losada.

Garin, E. (1981). La revolución cultural del renacimiento. Barcelona: Editorial Crítica.

Gaukroger, S. (2004). Francis Bacon and the transformation of early-modern philosophy. Cambridge: Cambridge University Press.

Gaukroger, S. (2006). The emergence of a scientific culture-sciene and the shaping of modernity 12101685. Oxford: Oxford University Press.

Horkheimer, M. y Adorno, T. (1994). Dialéctica de la ilustración: fragmentos filosóficos. Madrid: Trotta.

Koyré, A. (1981). Estudios galileanos. México: Siglo XXI Editores.

Kristeller, P. (1970). Ocho filósofos del renacimiento italiano. México: Fondo de Cultura Económica.

Larroyo, F. (1980). Estudio introductorio. En Instauratio Magna (pp. xi-xxix). Buenos Aires.

Menn, S. (2003). The intellectual setting. En D. Ayers y M. Garber (ed.), The Cambridge history of Seventeenth-century philosophy (pp. 33-86). Cambridge: Cambridge University Press.

Milner, B. (1997). Francis Bacon: the teological foundations of Valerius Terminus. Journal of the History of Ideas, 58, 245-264.

Mínguez Pérez, C. (2006). Filosofía y ciencia en el Renacimiento. Madrid: Síntesis.

Pérez-Ramos, A. (1999). Bacon's legacy. En M. Peltonen (ed.), The Cambridge companion to Bacon (pp. 311334). Cambridge: Cambridge University Press.
Pérez-Ramos, A. (1988). Francis Bacon's idea of science: and the maker's knowledge tradition. Oxford: Clarendon Press.

Reale, G. y Antiseri, D. (1988). Historia del pensamiento filosófico y científico. Barcelona: Herder.

Rees, G. (1999). Bacon's speculative philosophy. En M. Peltonen (ed.), The Cambridge companion to Bacon (pp. 121-145). Cambridge: Cambridge University Press.

Rees, G. (2002). Reflections on the reputation of Francis Bacon's philosophy. The Huntington Library Quarterly, 65, 379-304.

Rossi, P. (1990) Francis Bacon: de la magia a la ciencia. Madrid: Alianza.

Rossi, P. (1999). Bacon's idea of science. En M. Peltonen (ed.), The Cambridge companion to Bacon (pp. 25-46). Cambridge: Cambridge University Press.

Rossi, P. (2002). Francis Bacon and the humanistic aspects of modernity. En P. French y H. Wettstein (ed.) (2002), Midwest studies in philosophy. Renaissance and Early Modern Philosophy (pp. 124-139). Oxford: Blackwell.

Rossi, P. (2005). Virtues and the scientific revolutions. En N. Koertge (ed.), Scientific values and civic virtues (pp. 71-80). Nueva York: Oxford University Press.

Sargent, R. (1999). Bacon as an advócate or cooperative scientific research. En M. Peltonen (ed.), The Cambridge Companion to Bacon (pp. 146-171). Cambridge: Cambridge University Press.

Serrano, G. (2006). La querella en torno al silogismo 1605-1704: conocimiento versus forma lógica. Bogotá: Universidad Nacional de Colombia.

Tovey, G. (1952). Toward a new understanding of Francis Bacon's reform of philosophy. The Philosophical Review, 61, 568-574.

Urbach, P. (1993). Francis Bacon's philosophy of science. Illinois: Open Court. 